\title{
Dinâmica imobiliária e regulação ambiental: uma discussão a partir do eixo-sul da Região Metropolitana de Belo Horizonte*
}

\author{
Heloisa Soares de Moura Costa** \\ Mônica Campolina Diniz Peixoto***
}

\begin{abstract}
O trabalho traz, inicialmente, uma breve discussão teórica sobre a produção do espaço urbano e a emergência da regulação ambiental, principalmente no que diz respeito à expansão urbana. A seguir, são discutidos alguns instrumentos de regulação ambiental - em especial o licenciamento de atividades -, que têm feito emergir práticas sociais diversificadas, articulando interesses econômicos, o Estado e grupos sociais voltados para proteção ambiental. Enfatiza-se o caráter contraditório da intervenção do Estado e discutem-se os limites e possibilidades de ação dos movimentos sociais organizados em torno da reprodução das condições de expansão urbana. $O$ artigo utiliza o caso do crescimento metropolitano no eixo-sul de Belo Horizonte para evidenciar os conflitos em torno das formas de apropriação e uso do solo urbano, bem como os expedientes adotados pelo capital imobiliário para agregar valor ao produto, reforçando mecanismos conhecidos de elitização e exclusão. Discute-se, ainda, se há possibilidades de reversão de tal quadro a partir da participação e negociação dos conflitos entre os agentes sociais envolvidos.
\end{abstract}

Palavras-chave: Política ambiental. Mercado imobiliário. Participação. Conflito.

\section{Produção do espaço urbano e regulação ambiental}

Neste trabalho buscou-se contribuir para a compreensão das relações contemporâneas entre a atividade imobiliária e o Estado, tendo em vista, por um lado, o contexto atual da expansão urbana/metropolitana na sua versão de produção do espaço formal, que tem como público-alvo as camadas de alta e média renda da população e, por outro, as tendências atuais de regulação dos processos de expansão urbana/metropolitana, num momento de fragmentação da gestão urbana em diferentes contextos políticos locais (municipais) e crescente utilização de procedimentos usuais da política ambiental - como o licenciamento - para o controle do parcelamento do solo. Este debate assume contornos particulares no caso em análise - a expansão metropolitana ocorrida no chamado eixo-sul de Belo

\footnotetext{
* Este trabalho constitui resultado parcial das seguintes pesquisas desenvolvidas na UFMG: "A expansão metropolitana de Belo Horizonte: dinâmica e especificidades no eixo-sul", financiada pela FAPEMIG, pelo CNPq e pela PRPq/UFMG; e "Novas periferias metropolitanas: política e regulação urbano-ambiental na produção do espaço metropolitano", financiada pelo CNPq. Uma versão preliminar deste artigo foi apresentada ao XXIX Encontro Anual da Anpocs, no GT - Conflitos Sociais e Meio Ambiente.

** Arquiteta (FAU/UFRJ), doutora em Demografia (Cedeplar/UFMG), professora do Programa de Pós-Graduação em Geografia do IGC/UFMG e pesquisadora do CNPq.

${ }_{* * *}$ Arquiteta (EA/UFMG), mestre em Geografia (IGC/UFMG), analista ambiental da Feam - Fundação Estadual do Meio Ambiente de Minas Gerais.
} 
Horizonte -, por incorporar também outro elemento: a regulação da urbanização no interior de unidades de conservação de uso sustentável, como é o caso da APA Sul - Área de Proteção Ambiental ao Sul da Região Metropolitana de Belo Horizonte.

A expansão de Belo Horizonte apresenta algumas características da urbanização recente, materializada em termos espaciais em processos de fragmentação e dispersão do tecido urbano, associados a mecanismos de crescente segregação socioespacial.

A atividade imobiliária é considerada, tradicionalmente, um setor (uma fração) do capital de baixa tecnologia, pouco expressivo em termos de participação da vanguarda do processo de acumulação, porém de grande relevância para a canalização de poupanças e investimentos privados dispersos. Apesar de trazer ao debate relações sociais arcaicas associadas ao rentismo e à propriedade fundiária, ambos compreendidos, no quadro conceitual da economia política, como um entrave à fluidez da acumulação capitalista, o capital imobiliário vem há décadas operando em condições vantajosas diante de outros setores da economia, à medida que consegue influir em (e antecipar) ganhos decorrentes dos mecanismos formadores da renda da terra, particularmente a renda diferencial (LIPIETZ, 1974; TOPALOV, 1974; BALL, 1977).

Desde os anos 70 e durante as duas décadas que se seguiram, os estudos sobre dinâmica imobiliária e fundiária urbana produziram uma reflexão bastante consistente sobre a lógica de atuação dos agentes sociais na produção do espaço urbano, a partir da qual se buscava explicar a consolidação de um padrão de urbanização marcado pela desigualdade extrema, que se manifesta nas já bem conhecidas múltiplas formas de segregação socioespacial e informalidade/ilegalidade urbana. Mais recentemente, como parte da conhecida estratégia de produção de "novas mercadorias", fundamental para a sobrevivência do processo de acumulação e em consonância com os também bastante discutidos movimentos de enclausuramento e auto-segregação (CALDEIRA, 1997), os loteamentos fechados vêm se espalhando rapidamente pelo espaço urbano brasileiro, forjando novos conceitos de moradia, justificados pelo discurso da segurança e da qualidade ambiental (COSTA, 2003).

Não é novidade a utilização da natureza, assim como do corpo das mulheres (SHIVA, 2001), para a venda dos mais diversos produtos. O que se busca argumentar como pressuposto deste trabalho é que, no momento atual, não só a natureza, mas também os atributos e a qualidade ambiental do espaço vêm passando a fazer parte do produto imobiliário, agregando-lhe valor na forma de renda diferencial e, às vezes, de renda de monopólio.

Os estudos realizados sobre a expansão metropolitana de Belo Horizonte em sua porção sul apontaram alguns destes processos associados à modernização ecológica (HARVEY, 1996), ainda que tardia, do capital imobiliário na expansão urbana. São alguns exemplos: a crescente complexidade dos empreendimentos, congregando outros usos além do residencial, em especial aqueles associados a centros culturais e turismo de natureza; a criação de unidades de conservação de uso exclusivo, como as RPPN - Reservas Particulares de Patrimônio Natural; o parcelamento no interior de unidades de conservação de uso sustentável; a concepção (simplista, diríamos) dos empreendimentos com unidades autônomas, desvinculadas dos centros urbanos; o controle seletivo de densidades a partir de tipologias construtivas; e o uso do processo de licenciamento ambiental como uma espécie de "selo verde" legitimador do empreendimento.

Assim como o capital, o Estado também incorporou princípios da modernização ecológica, como a tendência crescente de utilização de procedimentos e instrumentos da legislação ambiental nos processos de regulação das atividades urbanas (COSTA, 2006). O licenciamento ambiental de loteamentos é o mecanismo discutido neste trabalho, tendo como estudo de caso o processo de licenciamento da segunda fase de expansão do empreendimento Alphaville Lagoa dos Ingleses, no município de Nova Lima, ao sul de Belo Horizonte. 
O referencial teórico mais amplo parte da noção de produção social do espaço e do urbano (LEFEBVRE, 1991; 1999), contemplando, entre outros, os seguintes aspectos:

- produção material do espaço, do ambiente construído, envolvendo sua base econômica, a infra-estrutura, as edificações, as materialidades, inclusive os espaços não construídos e de preservação;

- produção social da natureza, como ambiente transformado, muitas vezes materializada como paisagem na expansão urbana;

- produção e reprodução de valores, modos de vida, desejos e padrões de consumo;

- produção e reprodução de relações sociais, de mercado e de poder, muitas vezes "naturalizadas" e reproduzidas como privilégios, manifestações assimétricas materializadas espacialmente em várias formas de segregação e exclusão;

- reprodução de um aparato de regulação que estabelece regras e critérios para atuação dos agentes, construindo acordos de convivência, bem como instâncias de explicitação e negociação dos conflitos.

\section{O eixo-sul de expansão metropolitana de Belo Horizonte}

O padrão de expansão urbana que se desenvolveu no eixo-sul da Região Metropolitana de Belo Horizonte (RMBH), ultrapassando a barreira natural da Serra do Curral, apresenta características especiais se comparado com outros eixos de expansão metropolitana, destacando-se a estrutura fundiária altamente concentrada de propriedade de grandes empresas mi- neradoras, particularmente no município de Nova Lima, onde se encontram importantes áreas de proteção ambiental.

Enquanto o entorno imediato de Belo Horizonte e de suas áreas conurbadas, em especial Betim e Contagem, a oeste e na região norte, vivenciou uma significativa oferta de lotes para o mercado de baixa renda nas décadas de 70 e 80 , o eixo sul metropolitano foi palco da oferta de lotes para a população de média e alta renda, atraída pelos seus atributos ambientais, a princípio como segunda moradia para lazer de final de semana e, aos poucos, particularmente a partir dos anos 90, como local de moradia principal. Contribuiu para isso a intervenção do Estado na definição de investimentos em infra-estrutura, bem como políticas metropolitanas de uso, ocupação e parcelamento do solo dos anos 70 .

O município de Nova Lima apresenta uma situação especial no contexto da $\mathrm{RMBH}$, possuindo rico patrimônio natural, onde se destacam remanescentes de Mata Atlântica, rede hidrográfica densa com importantes mananciais destinados ao abastecimento da população metropolitana, reservas importantes de minério de ferro, beleza cênica e uma rica biodiversidade. Por outro lado, está localizado no entorno do Parque Estadual da Serra do Rola Moça e $93,11 \%$ do seu território está inserido no interior da APA Sul, ${ }^{1}$ área de proteção ambiental criada para a preservação de mananciais de importância estratégica para o abastecimento de água da $\mathrm{RMBH}$, de sua biodiversidade e do seu patrimônio cultural relacionado ao ciclo do ouro e à mineração. Além disso, no momento o eixo-sul encontra-se sob forte pressão da implantação de projetos urbanísticos destinados a empreendimentos imobiliários de grande porte. A Tabela 1 evidencia a participação do município de Nova Lima na APA Sul.

\footnotetext{
${ }^{1}$ A Área de Proteção Ambiental Sul da Região Metropolitana de Belo Horizonte foi criada pela Lei Estadual n. 13.960. De acordo com o art. 15, da Lei Federal n. 9.985, de 18 de julho de 2000, a criação de uma área de proteção ambiental tem por objetivo "[...] disciplinar seu processo de ocupação e assegurar a sustentabilidade do uso de seus recursos naturais". O mesmo art.15 define a área de proteção ambiental como "[...] uma área em geral extensa, com um certo grau de ocupação humana, dotada de atributos abióticos, bióticos, estéticos ou culturais especialmente importantes para a qualidade de vida e o bem-estar das populações humanas [...]".
} 
MAPA 1

Mancha urbana dos municípios da Região Metropolitana de Belo Horizonte 2002

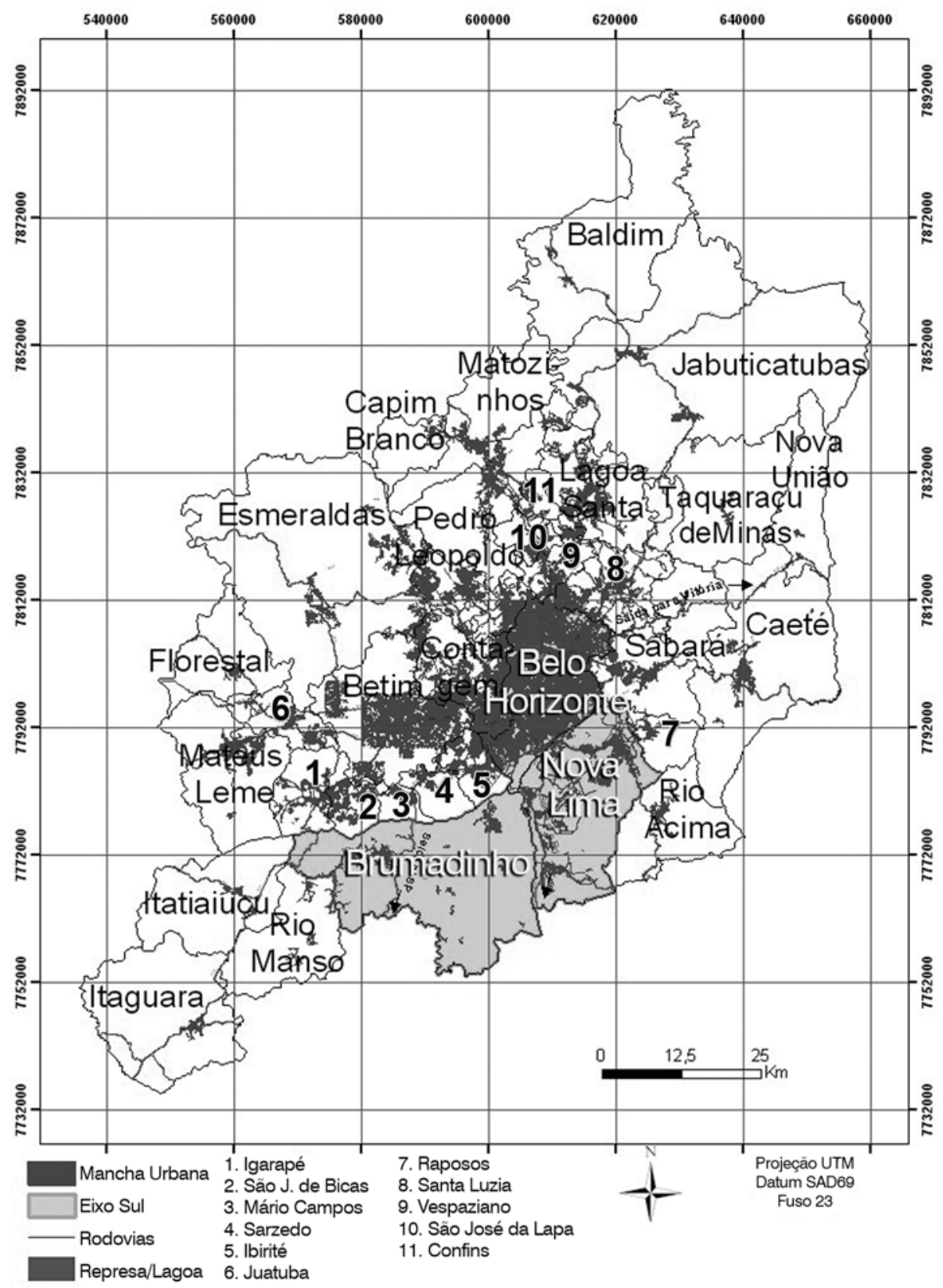

Fonte: Costa et al. (2006). 
TABELA 1

Participação dos Municípios na APA Sul da Região Metropolitana de Belo Horizonte

\begin{tabular}{|c|c|c|c|}
\hline Municípios & $\begin{array}{c}\text { Área total } \\
\text { (em hectares) }\end{array}$ & $\begin{array}{l}\text { Área do município na APA } \\
\text { Sul (em km²) }\end{array}$ & $\begin{array}{l}\text { Participação da área do município } \\
\text { no território da APA Sul (\%) }\end{array}$ \\
\hline Barão de Cocais & 34.056 & 3,9023 & 1,15 \\
\hline Belo Horizonte & 33.023 & 34,3340 & 10,40 \\
\hline Brumadinho & 64.008 & 182,4925 & 28,51 \\
\hline Caeté & 54.224 & 39,2172 & 7,23 \\
\hline Catas Altas & 23.821 & 74,5436 & 31,29 \\
\hline Ibirité & 7.366 & 17,6767 & 24,00 \\
\hline Itabirito & 54.415 & 260,6347 & 47,90 \\
\hline Mário Campos & 3.506 & 11,4229 & 32,58 \\
\hline Nova Lima & 42.845 & 398,9391 & 93,11 \\
\hline Raposos & 7.159 & 39,4054 & 55,04 \\
\hline Rio Acima & 22.784 & 227,8400 & 100,00 \\
\hline Santa Bárbara & 68.471 & 338,6535 & 49,46 \\
\hline Sarzedo & 6.217 & 22,5402 & 36,26 \\
\hline
\end{tabular}

Fonte: Zoneamento Ecológico-Econômico da APA Sul RMBH, 2003, em elaboração.

De acordo com a legislação ambiental vigente, além do porte, pelo fato desses empreendimentos se localizarem no interior de unidade de conservação estadual e na região metropolitana, o licenciamento ambiental é obrigatório e é realizado na esfera do Copam.

Localizam-se no município as seguintes unidades de conservação que são áreas de proteção de mananciais: Estação Ecológica de Fechos, Reserva da Mutuca, Mata Capitão do Mato e Mata do Tumbá. Existem ainda duas Reservas Particulares de Patrimônio Natural (RPPN), ambas em áreas das empresas mineradoras: a Mata do Jambreiro, de propriedade da Minerações Brasileiras Reunidas (MBR, hoje CVRD); e outra RPPN, criada recentemente no loteamento Vale dos Cristais, pertencente à Anglo Gold, ${ }^{2}$ durante o processo de licenciamento ambiental no Copam, como medida compensatória para concessão da Licença Prévia.
Tais áreas, localizadas no entorno do Parque Estadual da Serra do Rola Moça, de acordo com a legislação correlata, ${ }^{3}$ exigem dos empreendimentos que pretendem se instalar na denominada zona de amortecimento 4 de área natural protegida a manifestação prévia favorável do órgão gestor da unidade de conservação, no caso o Instituto Estadual de Florestas de Minas Gerais (IEF-MG). O cumprimento dessa exigência pode acarretar modificações na legislação urbanística municipal, tendo em vista que alguns usos e modelos de ocupação do solo podem ser considerados inadequados aos objetivos de preservação do parque e, até mesmo, justificar o indeferimento da licença ambiental ou impedir a manifestação prévia favorável do órgão gestor do parque quanto à sua localização.

Por outro lado, a localização no interior da APA Sul impõe, ainda, restrições quanto aos usos e ocupação do solo, pois, embora a APA seja uma unidade de conservação de

\footnotetext{
2 Diante da perspectiva de esgotamento da mineração, a empresa vem diversificando suas atividades e investindo no mercado imobiliário metropolitano, a partir de projetos de grande envergadura, associando áreas residenciais, comércio e serviços e unidades de conservação.

${ }^{3}$ A Lei n. 9.985 de 18/07/2000 institui o Sistema Nacional de Unidades de Conservação - SNUC.

${ }^{4}$ A zona de amortecimento, estabelecida na Lei n. 9.985, de 18 de julho de 2000, é definida no art. 2o, inciso XVIII como "[...] o entorno de uma unidade de conservação, onde as atividades humanas estão sujeitas a normas e restrições específicas, com o propósito de minimizar os impactos negativos sobre a unidade [...]".
} 
uso sustentável que admite determinados usos em seu interior, ${ }^{5}$ existe um rigor maior na análise dos estudos de impacto ambiental e das respectivas medidas mitigadoras durante o processo de licenciamento ambiental. Acrescentam-se a essas restrições os conflitos entre o poder público estadual, o mercado e a comunidade, em decorrência de interesses divergentes em torno do processo de ocupação do solo no território municipal, dividido entre mineração, residência, comércio e serviços de médio e grande portes e a proteção ambiental.

\section{Licenciamento ambiental e expansão urbana}

Instituído em Minas Gerais em 1980, pela Lei Estadual n. 7.772/1980, o licenciamento ambiental voltou-se inicialmente para as atividades produtivas dos setores primário (mineração) e secundário (indústrias de transformação), motivado pela crescente mobilização da sociedade em torno das ameaças à qualidade de vida ocasionadas pela poluição atmosférica e hídrica.

Desde a década de 70, a associação entre poluição e qualidade do ambiente urbano já apontava a necessidade de regulação ambiental da urbanização em moldes semelhantes ao das atividades produtivas, cujo controle, em princípio, levaria a uma melhoria geral das condições de vida da população. Entretanto, nesse período inicial de percepção das questões ambientais, predominou a visão segundo a qual qualquer transformação no ambiente natural constituía uma fonte de deterioração ambiental.

Nesta perspectiva, a ocupação urbana, cuja produção engloba em grande medida processos artificiais, seria, por definição, causadora da degradação ambiental. ${ }^{6}$ Foi só a partir de meados da década de 80 que esta visão começou a se transformar ${ }^{7}$ e ganhou corpo a hipótese de a gestão urbana se consolidar como uma ação de proteção ambiental. No nível da regulação, as questões relacionadas à urbanização passam a ser consideradas na prática da gestão ambiental, com a publicação da Resolução Conama n. 01/86, que listou como atividades sujeitas ao estudo prévio de impacto ambiental os projetos urbanísticos, entre os quais o parcelamento do solo urbano destinado ao uso residencial.

Entretanto, a possibilidade de utilização dos instrumentos de gestão ambiental para impedir a realização de empreendimentos imobiliários de grande porte tem sido bastante remota, a exemplo do que tradicionalmente acontece com o licenciamento de atividades produtivas (industriais, minerárias, etc.) ou de grandes projetos de infra-estrutura, como as barragens.

A própria noção de licenciamento remete ao estabelecimento das condições nas quais se dará o empreendimento a ser licenciado, e não à decisão acerca do empreendimento acontecer ou não - a famosa opção zero - ou a estudos prévios de planejamento das atividades. Está implícita a noção de que há sempre uma solução técnica adequada, uma certa fé na tecnologia (GIDDENS, 1991). Igualmente presente está a lógica de mercado, que constitui a racionalidade implícita no estabelecimento de grande parte das medidas compensatórias. ${ }^{8}$

No caso da expansão urbana via parcelamento do solo, as restrições de natureza técnica, relacionadas à ocupação de áreas frágeis e/ou de importância para o equilíbrio dos ecossistemas, usualmente reduzemse à busca de uma alternativa tecnológica adequada à redução do impacto negativo

\footnotetext{
${ }^{5}$ A Lei Federal n. 9.985, de 18 de julho de 2000, que institui o Sistema Nacional de Unidades de Conservação - SNUC, define a APA como uma unidade destinada a proteger a diversidade biológica mediante a regulação do processo de ocupação e a garantia do uso sustentável dos recursos naturais ( art. 15).

6 Os relatórios do Banco Mundial, no início da década de 70, explicitam essa relação, que foi incluída nas justificativas para a incorporação da questão urbana como uma questão ambiental na elaboração do II Plano Nacional de Desenvolvimento (1974), conforme lembram Lysia Bernardes (1986) e Marilia Steinberger (2000).

7 Ver, por exemplo, Monte-Mór (1994) para um questionamento da idéia de espaço urbano como "espaço morto". Ver também a interessante contribuição de Swyngedouw (2001) sobre a urbanização cyborg, um híbrido de processos naturais e artificiais, de natureza e tecnologia.

8 Ver Zhouri, Laschefski e Paiva (2005) para uma crítica ao procedimento do licenciamento ambiental.
} 
e, em caso de destruição de patrimônio irrecuperável, como passíveis de negociação de medidas compensatórias para situações de exceção. Raramente são discutidas alternativas para o empreendimento e, dependendo dos potenciais impactos ambientais negativos da atividade, a adoção de medidas compensatórias é um paliativo. As medidas adotadas, propostas pelo empreendedor, nem sempre privilegiam as áreas próximas ao empreendimento diretamente afetadas, buscando, de forma clara, não prejudicarem os investimentos.

Os procedimentos para o licenciamento ambiental são definidos em leis e deliberações, com certa flexibilidade de negociação para os conflitos explicitados, considerandose que o fórum de decisão é um conselho - o Conselho Estadual de Política Ambiental (Copam) ou os Conselhos Municipais de Meio Ambiente, nos casos de competência decisória no âmbito municipal. ${ }^{9}$

\section{A regulação do parcelamento do solo}

O Estado assumiu, num primeiro momento, uma estratégia de gestão baseada na produção de leis e normas, sintetizadas a seguir, que constituem a fundamentação jurídica para atuação do Estado no âmbito urbanístico e ambiental.

Embora a legislação florestal, a de recursos hídricos e a urbanística, vigentes no Brasil a partir de meados da década de 30 , reunissem condições para regular a ocupação adequada do solo urbano, normas específicas para o controle da poluição e da degradação ambiental somente se concretizaram no início da dos anos 80, influenciadas pelos resultados da Primeira Conferência das Nações Unidas sobre o Meio Ambiente (Estocolmo, 1972) e pela proposta do II Plano Nacional de Desenvolvimento (II PND) em 1974.

Logo após a publicação da lei federal sobre o parcelamento do solo urbano - Lei n. $6.766 / 79$ - em 1979, foram elaboradas e aprovadas, na década de 80 , as legislações federal e estadual do meio ambiente, com o objetivo de definir as diretrizes da política ambiental brasileira. Além da publicação de normas e padrões de qualidade ambiental, foram definidos como instrumentos de gestão: a avaliação de impacto ambiental; o zoneamento ambiental; o licenciamento ambiental; a criação de unidades de conservação; e os conselhos de meio ambiente, instâncias deliberativas que objetivavam garantir a participação social no processo decisório. O Estado de Minas Gerais, um dos pioneiros na gestão ambiental, publicou em 1980 a Lei Estadual n. 7.772, que definiu as diretrizes para sua atuação na área ambiental e contribuiu para elaboração da legislação federal, publicada em 1981: a Lei n. 6.938.

O controle da expansão urbana/metropolitana é feito com a participação formal do Estado, de acordo com as normas vigentes. ${ }^{10}$ Diretrizes de planejamento metropolitano, baseadas em parâmetros de análise definidos ainda nas décadas de 70 e 80 , vigoram até os dias atuais e não foram atualizadas, desconsiderando o estágio atual do processo de metropolização de Belo Horizonte e as alterações introduzidas na legislação urbanística e ambiental.

Agrava essa situação a inexistência de um fórum de debate sobre a região metropolitana, capaz de subsidiar o planejamento e a gestão municipal, a elaboração e implementação de planos diretores, ou ainda auxiliar na análise de processos de licenciamento de atividades urbanas, entre as quais o parcelamento do solo. $O$ resultado é um processo de expansão urbana fragmentado e desarticulado, comandado prioritariamente pelos interesses do capital imobiliário/fundiário, que tem agravado a vulnerabilidade física, ambiental e urbana da região. Em conseqüência, alguns problemas são desencadeados, podendo-se citar,

\footnotetext{
${ }^{9}$ Ver Peixoto (2005) para uma análise detalhada das legislações urbanística e ambiental associadas ao parcelamento do solo urbano e, em especial, dos procedimentos para o licenciamento ambiental de loteamentos.

${ }^{10}$ A Deliberação n.16, de 05 de junho de 1981, estabeleceu as normas para o parcelamento do solo na RMBH, mediante deliberação do conselho deliberativo da RMBH, tendo como referência a recém aprovada Lei federal de Parcelamento do Solo, a Lei n.6766/79.
} 
entre outros, ocorrência de assentamentos humanos em áreas ambientalmente frágeis, desatenção à capacidade de suporte do sítio natural e das estruturas instaladas, intensa especulação imobiliária e ilegalidade da ocupação de áreas periféricas, insuficiência de serviços públicos, desarticulação institucional, escassez de recursos humanos e financeiros e desinformação e omissão da decisão política, resultando na ineficiência do setor público no controle do processo de expansão urbana e ausência de mecanismos efetivos de participação social na administração e construção da metrópole.

$\mathrm{O}$ controle das fontes poluidoras ${ }^{11}$ é realizado mediante o Licenciamento Ambiental, que avalia a viabilidade ambiental de um empreendimento nas etapas de planejamento, instalação, funcionamento e ampliação, para a concessão das respectivas Autorização de Funcionamento e Licenças Prévia - LP,12 de Instalação - LI e de Operação - LO, ${ }^{13}$ após apreciação do Conselho Estadual de Política Ambiental (Copam), fundamentada nos respectivos pareceres técnico e jurídico.

Para cumprir suas funções, o Copam conta com o suporte técnico dos demais órgãos que integram o sistema de gestão ambiental em Minas Gerais: a Fundação Estadual do Meio Ambiente (Feam) e o Instituto Estadual de Florestas (IEF-MG), que possuem atribuições específicas definidas em lei. ${ }^{14}$ Embora fossem parceiros no sistema desde 1998, a atuação desses órgãos vinha sendo feita de forma desarticulada e às vezes controversa. Esse fato tem gerado críticas da sociedade civil com relação aos procedimentos e resultados alcançados no cumprimento de suas funções. De fato, análises mais recentes têm apontado para mudanças de postura do Copam, inicialmente palco de explicitação de conflitos, na direção de posturas mais conciliatórias e orientadas para a formação de consensos (CARNEIRO, 2005).

Em que pesem as críticas aos procedimentos adotados e à morosidade e rigor nas análises dos processos, na visão dos empreendedore ${ }^{15}$ o licenciamento ambiental permite

[...] planejar e implantar de forma sistemática e efetiva as medidas e sistemas de controle ambiental, propiciando qualidade aos assentamentos humanos. É a oportunidade do empreendedor avaliar os riscos e oportunidades do seu empreendimento.

\section{Por outro lado,}

[...] obriga que os empreendedores melhorem a qualidade de seus projetos. [...] Com o nível de exigência alto, somente aqueles que trabalham corretamente podem permanecer no mercado. E, conseqüentemente, existe uma elevação na qualidade dos assentamentos humanos.

Há uma clara ambigüidade entre o discurso dos empreendedores, ao reconhecerem a importância do licenciamento ambiental, e a prática marcada pela tendência à implantação dos empreendimentos à margem da legislação vigente, optando pela ilegalidade como forma de diminuir seus custos e, segundo eles mesmos, reduzir dessa forma o custo final do seu

\footnotetext{
11 São fontes poluidoras, de acordo com do Decreto n. 39.424/1998, "[...] qualquer atividade, sistema, processo, operação, maquinaria, equipamento ou dispositivo, móvel ou não, que induza, produza ou possa produzir poluição" (MINAS GERAIS, 1998, Art. 3ㅇ, § 1ㅇ).

12 Considera-se a Licença Prévia a etapa mais importante do licenciamento ambiental, pois permite a discussão dos possíveis efeitos da implantação da atividade no espaço e das propostas para minimizar ou evitar os impactos negativos decorrentes da implantação e ocupação do loteamento. Tal importância é maior quando os municípios e a região não possuem diretrizes de ocupação previamente definidas que incorporem a regulação da expansão urbana em áreas de proteção ambiental.

13 O Copam é um órgão normativo, colegiado, consultivo e deliberativo subordinado à Secretaria de Meio Ambiente e Desenvolvimento Sustentável de Minas Gerais (Semad), responsável pela implementação da política ambiental do Estado. É constituído por representantes dos diversos segmentos da sociedade.

14 O Decreto n. 39.424/1998 estabelece as competências no licenciamento e fiscalização ambiental em Minas Gerais. De acordo com o art. 5o, parágrafo único, cabe à Feam o controle das atividades industriais, minerárias e de infra-estrutura (aqui está inserido o licenciamento do parcelamento do solo) e, ao IEF-MG, o controle das atividades agrícolas, pecuárias e florestais.

15 Opiniões obtidas através de questionário, visando coletar informações sobre a visão dos usuários do licenciamento ambiental no Estado de Minas Gerais.
} 
produto. As características do mercado fundiário/imobiliário para o qual o produto é direcionado constituem um elemento importante na composição do preço final e, portanto, na viabilidade econômica de adoção, por parte do empreendedor, dos parâmetros exigidos pelo licenciamento ambiental. Dito em outros termos, a realização de empreendimentos imobiliários com observância dos critérios exigidos garante um determinado padrão de qualidade ao produto, mas eleva o investimento realizado, encarecendo o produto final. No limite, chega-se ao paradoxo segundo o qual a observância da regulação urbanística e ambiental, no caso da atividade imobiliária, agrega valor ao produto, encarecendo-o e, conseqüentemente, elitizando-o e tornando-o inacessível para os segmentos mais pobres da população.

A regulação que em princípio deveria garantir padrões mínimos de urbanização para todos, num contexto de exclusão socioeconômica e de falta de alternativas habitacionais de massa, ao desencadear o gatilho do preço da terra, acaba por tornar o acesso à mesma (e à cidade) uma meta ainda mais distante para muitos. No caso de empreendimentos em áreas de proteção ambiental, em que os atributos ambientais do meio natural contribuem para o aumento das restrições e cuidados na realização do parcelamento, acrescenta-se ao processo a renda diferencial gerada pelo monopólio do usufruto da natureza, materializada como paisagem, o que contribui para uma espiral ascendente de valorização.

Assim, diferentemente de uma mercadoria produzida em série por uma indústria, o produto final deste processo de licenciamento de parcelamento do solo é o lote e, em última análise, o espaço urbano, que se diferencia especialmente pelos atributos de localização aos quais se atribui uma valoração segundo sua posição na divisão social e econômica do espaço (LIPIETZ, 1974). A discussão sobre o licenciamento ambiental de atividades imobiliárias necessita ser articulada com a compreensão das formas e processos de produção social do espaço, bem como pela explicitação dos papéis desempenhados e interesses associados a cada um dos agentes sociais que participam de tal processo (SINGER, 1973; LOJKINE, 1981). Da mesma forma, os procedimentos e metodologias utilizados no licenciamento necessitam incorporar esta dimensão, sob o risco de se transformarem em procedimentos inócuos ou em arenas nas quais os debates explicitados não traduzem os reais conflitos existentes entre os atores. $O$ caso do licenciamento ambiental do empreendimento Alphaville Lagoa dos Ingleses, localizado no município de Nova Lima, no eixo-sul de expansão metropolitana de Belo Horizonte, fornecerá um interessante exemplo destes dilemas.

\section{Licenciamento ambiental no eixo-sul de expansão metropolitana: o caso do Alphaville 2 em Nova Lima}

\section{Antecedentes}

Como na maioria dos municípios brasileiros, a aprovação de loteamentos no município de Nova Lima adotou como referência o Decreto-lei n. 58/37, cujas exigências limitavam-se à definição dos limites do loteamento, do traçado das ruas e de um parecer sanitário e militar, se fosse o caso. $\mathrm{Na}$ aprovação dos loteamentos

[...] não se especificavam exigências sanitárias a serem observadas [...] Os espaços públicos, na prática [...] eram somente as ruas. Deixavam de exigir equipamentos urbanos e comunitários, tais como faixas non aedificandi e locais destinados ao lazer, à saúde, à cultura. Os loteamentos só interessavam ao direito civil. [O que significava] [...] ressalvar o comprador em seus direitos imediatos quanto à propriedade imobiliária [...] (MACHADO, 1998, p.117).

Considerações como declividades, tipo de solo, vegetação, nascentes e cursos d'água não eram analisadas no processo de aprovação. Essa situação produziu, no território de Nova Lima, ocupação do solo em áreas de risco potencial, sujeitas a escorregamento de encostas e ocorrência de enchentes nas regiões onde foram realizadas obras de regularização e canalização de rios, ocupando as várzeas dos cursos d'água. O descumprimento dos disposi- 
tivos do Código Florestal contribuiu para a ocupação de áreas inadequadas em termos da segurança da população e evidenciou a ausência de integração entre os órgãos responsáveis pela aplicação da legislação.

Com a criação da Região Metropolitana de Belo Horizonte, em 1973, e de seu órgão de suporte técnico, o Plambel, houve uma tentativa de tratamento conjunto com os municípios, das questões urbanas e ambientais, particularmente no que se refere ao controle da expansão urbana, ao transporte público, à habitação e ao saneamento. No entanto, na década de 80 , o sistema de planejamento metropolitano mostrou sua fragilidade, e essas questões foram tratadas de forma isolada, embora os potenciais impactos negativos afetassem a região em sua totalidade. Segundo Mares Guia (2000, p.412),

[...] a crise financeira e o início do processo de redemocratização vêm expor as brechas político-institucionais do sistema [...] A carência de recursos públicos tem como conseqüência imediata o estancamento dos investimentos federais nas regiões metropolitanas [...] o processo de redemocratização propicia o estabelecimento de novas relações de poder, fortalecendo novos atores sociais, em especial as prefeituras e os movimentos sociais.

Somente durante o processo de criação da APA Sul, no período de 1992 a 1994, evidenciou-se algum fortalecimento dos movimentos sociais na região, especialmente os ambientalistas, articulados em torno da proteção ambiental e da formalização da unidade de conservação. Desde os anos 70, em Belo Horizonte, o movimento ambientalista desempenhou papel ativo na institucionalização da preservação ambiental, a exemplo do tombamento da Serra do Curral e, posteriormente, da criação da APA
Sul. ${ }^{16}$ Os insuperáveis conflitos de interesse envolvendo proprietários fundiários, o setor minerário, os interesses coletivos e difusos de preservação dos aqüíferos de abastecimento metropolitano e do rico patrimônio ambiental de forma mais ampla são alguns dos elementos que vêm retardando o estabelecimento de um Zoneamento EcológicoEconômico para a APA (CAMARGOS, 2004; FREITAS, 2004).

A partir de 1994, os primeiros loteamentos foram encaminhados ao licenciamento ambiental, especialmente aqueles que pretendiam se instalar no município de Nova Lima, onde ocorreu a maior pressão para ocupação. A participação da Sedru/MG, que sucedeu a Seplan, nesse sentido foi decisiva, pois vinculou a liberação da anuência prévia para os loteamentos aí localizados à obtenção da Licença de Instalação do Copam, segunda etapa do processo de licenciamento ambiental, após o fornecimento das diretrizes metropolitanas.

O licenciamento de loteamentos em Nova Lima, entretanto, é ainda pouco representativo no total de licenciamentos do conjunto das atividades econômicas. Dos 100 empreendimentos localizados no município, licenciados ou em processo de licenciamento no Copam a partir de 1977,17 foram registradas apenas dez solicitações de licenciamento ambiental de loteamentos urbanos. Em consulta ao setor de documentação do Copam, verificou-se que esses empreendimentos somente foram encaminhados ao licenciamento ambiental a partir de 1995, portanto após a criação da APA Sul.

Entre os dez loteamentos objeto de solicitação de licenciamento ambiental no município de Nova Lima, toma-se como

\footnotetext{
${ }^{16}$ A região foi palco de uma das primeiras mobilizações motivadas pela questão ambiental na Região Metropolitana de Belo Horizonte, no final da década de 70 . O movimento alertava para a destruição da Serra do Curral, situada na divisa dos municípios de Belo Horizonte e Nova Lima, por uma mineradora e seus impactos negativos na paisagem. Para o processo de tombamento da Serra do Curral, ver Ferreira (2003). Ver Somarriba (1984) para uma análise dos movimentos sociais em Belo Horizonte nos anos 80.

17 Em 1977, o governo de Minas Gerais iniciou o controle ambiental de atividades de potencial impacto poluidor, com a criação da Comissão Estadual de Política Ambiental, cujo órgão executivo era a Superintendência de Meio Ambiente (SMA). É no mínimo curioso apontar que o parcelamento do solo, ou seja, a atividade que dá origem ao espaço urbano tenha a necessidade de licenciamento justificado pelo potencial poluidor que a cidade representa e não pelo fato de o licenciamento buscar garantir condições adequadas de habitabilidade do espaço resultante do parcelamento, ou de avaliação das conseqüências do aumento das demandas por investimentos públicos em decorrência de novos fluxos de pessoas, veículos, mercadorias ou serviços.
} 
TABELA 2

Processos no Copam para obtenção de licença ambiental, segundo atividades

2004

\begin{tabular}{lc}
\hline Atividades & Processos no Copam \\
\hline Mineração & 33 \\
Industria de transformação & 19 \\
Infra-estrutura & 05 \\
Comércio e serviços & 31 \\
Loteamentos & 10 \\
Outros & 02 \\
Total & $\mathbf{1 0 0}$ \\
\hline
\end{tabular}

Fonte: Feam, 2004.

referência o empreendimento imobiliário Alphaville 2, uma expansão do Alphaville Lagoa dos Ingleses (agora denominado 1), loteamento fechado situado às margens da Lagoa dos Ingleses, no interior da APA Sul. A referência para a análise são os estudos elaborados para o licenciamento ambiental do empreendimento, exigidos na legislação para avaliação da viabilidade ambiental de sua implantação.

\section{Alphaville 2: palco de conflitos}

O Alphaville Lagoa dos Ingleses, etapa 2, localiza-se na porção sul do município de Nova Lima, a cerca de $25 \mathrm{~km}$ de Belo Horizonte-MG, às margens da Lagoa dos Ingleses, na proximidade do trevo rodoviário para Ouro Preto, na BR-040 - BH/Rio, tendo como acesso principal a rodovia BR-356, sentido Ouro Preto.

A primeira etapa do Alphaville foi aprovada em 1999, compreendendo uma área de 430 hectares, dividida em 1.642 lotes, 1.545 dos quais, com tamanhos variando entre 700 e $1.500 \mathrm{~m}^{2}$, destinados a residências unifamiliares e distribuídos em unidades muradas independentes, denominadas residenciais. Os demais lotes, lindeiros ao sistema viário principal, são destinados a atividades terciárias, com possibilidade de verticalização. Há ainda um conjunto padronizado de 51 casas geminadas, denominadas town houses, além de um centro comercial composto por 228 lojas e salas. $O$ empreendimento pertence à Alphaville Urbanismo S.A, empresa que já realizou 31 projetos urbanísticos semelhantes no Brasil. A terra originalmente pertencia à MBR - Minerações Brasileiras
Reunidas -, detentora de parcela significativa de terras em Nova Lima, inclusive do entorno do empreendimento. Segundo os empreendedores, o projeto é "economicamente viável, ecologicamente correto e urbanisticamente perfeito" (ALPHAVILLE, 2004 apud LASCHEFSKI, 2006).

O empreendimento foi lançado em março de 1998 e entregue em 2000 com infra-estrutura completa: ruas asfaltadas e arborizadas, praça com tratamento paisagístico, áreas verdes preservadas, guaritas de segurança, iluminação pública, rede de água, estação de tratamento de esgoto e ciclovias. Antes mesmo do lançamento oficial, $90 \%$ dos 1.545 lotes haviam sido vendidos em apenas 90 dias, embora o processo de ocupação, atualmente em torno de $20 \%$, venha se dando de forma muito mais lenta do que previsto inicialmente. Cerca de metade dos lotes foi comprada apenas como investimento, o que vem repercutindo na dificuldade de viabilização econômica das atividades de comércio e serviços lá instaladas, originalmente atraídas pela previsão de um mercado consumidor muito mais amplo do que o que existe efetivamente (LASCHEFSKI, 2006; REZENDE, 2004; VILLASCHI, 2003).

O Alphaville, desde sua primeira etapa, é um empreendimento emblemático para o licenciamento ambiental de loteamentos, dada a complexidade de sua proposta e por ser o primeiro empreendimento desse porte a se instalar no interior de uma unidade de conservação de uso sustentável em Minas Gerais, a APA Sul. Além de passar por todas as etapas do licenciamento ambiental, pela primeira vez, foram explicitados os conflitos e os questionamentos sobre a adequação 
dos estudos ambientais à realidade urbana.

O EIA/Rima elaborado pela empresa explicita objetivos sobre a busca de autonomia $\mathrm{e} o$ atendimento às diretrizes de desenvolvimento municipal naquele momento, voltadas para atrair população de alta renda e comércio e serviços sofisticados.

O porte do empreendimento - a segunda etapa representa uma área de expansão de 340ha e o projeto completo, quando implantado, corresponderá a uma cidade de cerca de 27 mil habitantes ${ }^{18}$ - e sua pretendida autonomia, definida pela possibilidade de instalação de atividades de comércio e serviços, colocaram os órgãos responsáveis pelo licenciamento ambiental diante de uma nova realidade: o licenciamento de um empreendimento com um número elevado de habitantes, concentração de serviços sofisticados, áreas homogêneas, que pretendem "[...] dispensar a cidade" (CALDEIRA, 1997). Embora seja divulgada a imagem de uma "ilha" de paz, tranqüilidade e segurança, a dependência de mão-de-obra e de outros centros de comércio e serviços, algumas vezes dos serviços disponibilizados pela administração municipal, colocam em cheque essa dita autonomia. Essas questões deram origem a divergências e conflitos entre os empreendedores, a equipe técnica responsável pelo licenciamento e organizações da sociedade civil.

Os responsáveis pelo empreendimento advogavam (convenientemente) o tratamento do projeto urbanístico como uma unidade isolada, conforme idealizado e divulgado no material promocional do projeto, dispensando, portanto, a análise prospectiva das relações com os demais núcleos urbanos e a sede municipal. Ou seja, ao tratar um projeto urbanístico que se instala numa determinada região como uma unidade autônoma, os empreendedores buscavam diferenciá-lo e, assim, evitar a adoção dos procedimentos do licenciamento ambiental convencional, como o de uma atividade industrial, com limites e responsabilidades bem definidas com relação ao atendimento às exigências, como, por exemplo, aquelas relacionadas ao destino de efluentes e resíduos.

A aprovação da primeira etapa do empreendimento pelo Copam se fez após uma série de negociações, mediante uma listagem extensa de condicionantes, e contou com a participação decisiva de representantes de entidades ambientalistas. Críticas foram feitas à decisão de aprovar o empreendimento, pois o número de condicionantes da etapa de concessão de licença prévia significava que não tinham sido apresentados dados suficientes para a conclusão das análises, ou que o empreendimento não teria tido sua viabilidade ambiental comprovada.

Durante a primeira etapa de implantação do Alphaville, os empreendedores foram autuados várias vezes por descumprimento de condicionantes do Copam e por terem sido iniciadas a comercialização dos lotes e a ocupação do empreendimento sem a obtenção da licença respectiva. Segundo documentos integrantes do processo administrativo, até março de 2003 , os condicionantes ainda não haviam sido cumpridos, principalmente aqueles que dependiam da parceria com a Prefeitura Municipal de Nova Lima, como a instalação de aterro sanitário no município que receberia os resíduos sólidos gerados no empreendimento. Esses aspectos, entre outros, foram levantados na audiência pública realizada por solicitação da Associação Mineira de Defesa do Ambiente - Amda, durante a análise do EIA-Rima para a segunda etapa.

No que se refere à etapa 1 , o que não podemos deixar de abordar, já que a licença ambiental, na verdade, é uma concessão da sociedade ao empreendedor para utilizar recursos naturais que são de todos, é lembrar que existem condicionantes ainda não cumpridas, citando entre elas por exemplo, a implantação de reserva florestal e [...] a destinação final de resíduos sólidos [...] (Relatório da Audiência Pública do Alphaville 2, realizada em Nova Lima, em 06/05/2004).

\footnotetext{
18 Números apresentados pela Associação Mineira de Defesa do Meio Ambiente - Amda, durante a "Audiência pública Alphaville - Lagoa dos Ingleses, Fase II”, Nova Lima, 06/05/04 (LASCHEFSKI, 2006).
} 
Esses antecedentes evidenciam as dificuldades enfrentadas pelo órgão responsável pela análise ambiental - Feam -, quando foi protocolada a solicitação de licença prévia para a etapa 2 do loteamento, objeto desse estudo.

O foco das discussões é o possível impacto negativo de um parcelamento desse porte - uma cidade - no seu entorno. Como precisar a área indiretamente afetada após a consolidação do empreendimento e fazer prognósticos quanto ao seu futuro? Essa discussão foi encaminhada pela Associação Mineira de Defesa do Ambiente - Amda, em várias oportunidades, quando cobrou que o Copam deveria exigir do empreendedor a elaboração de planos diretores para os municípios de Bruma-dinho (incluindose seu distrito Piedade do Paraopeba) e Itabirito, considerados os mais afetados pelo empreendimento. Outras entidades ambientalistas e moradores das redondezas temem a ocorrência de uma "urbanização descontrolada nos arredores do condomínio", sendo que "um agravante nesse contexto é o centro comercial projetado para atender, além dos moradores, também as cidades vizinhas que se situam no entorno de aproximadamente $15 \mathrm{~km}$.

Em decorrência de todos esses fatores, durante a Audiência Pública, foi solicitada a elaboração de um Plano Diretor para a região" (LASCHEFSKI, 2006). Tal temor é bastante presente no caso dos municípios de Brumadinho e Itabirito, mas é pouco apontado por Nova Lima, por dois motivos: a sede urbana situa-se a uma distância considerável do empreendimento; e a intensa concentração fundiária por parte das empresas mineradoras no município, inclusive no entorno imediato do Alphaville, impede a ocupação por urbanização espontânea. Esta já começa a ocorrer nos distritos e povoados de Brumadinho (MENDONÇA; PERPÉTUO; VARGAS, 2004), com tendência a se intensificar principalmente após a implantação da segunda fase do empreendimento. ${ }^{19}$ Tais questões de caráter metropolitano e regional escapam totalmente às exigências do licenciamento ambiental, fortemente voltado para o interior do empreendimento e, no máximo, seu entorno imediato.

É bem verdade que não existiam as orientações de um plano diretor de Nova Lima na ocasião do processo de licenciamento e havia interesse da administração municipal daquele momento em sua aprovação, pois em várias oportunidades os representantes do município compareceram às reuniões do Copam para se manifestarem favoravelmente pela sua aprovação. Curioso ressaltar que, durante a audiência pública, havia uma faixa de apoio ao empreendimento, assinada pela então Prefeitura Municipal de Nova Lima, entre as inúmeras outras estendidas pelas paredes do auditório.

A ausência de diretrizes metropolitanas foi citada em todas as oportunidades, pois, sem essa referência, os impactos ambientais negativos sobre as estruturas urbanas ou rurais dos municípios vizinhos são o resultado de especulações sobre o futuro que os municípios não parecem dispostos a enfrentar.

Uma das questões que dificultam a análise ambiental de loteamentos fechados refere-se à inexistência de parâmetros urbanísticos tradicionalmente adotados para sua aprovação, como, por exemplo, livre circulação da população, existência de áreas públicas e independência vinculada a uma autogestão que na prática não existe. Quem fará a coleta e o destino final do lixo urbano? De quem é a responsabilidade pelo atendimento à demanda por transporte público, ensino fundamental, postos de saúde?

O Estado, como agente regulador, tem contribuído para a manutenção dessas pseudo "ilhas urbanas", homogêneas e desarticuladas. A atuação do capital imobiliário na região tem disseminado "uma cultura da moradia essencialmente antiurbana, alimentada simultaneamente pelo sonho do retorno à natureza e pela ilusão da segurança nos condomínios fechados" (COSTA, 2003, p.159).

\footnotetext{
19 Estima-se a geração de 9.000 empregos durante a construção (incluindo a fase 2) e cerca de 1.000 empregos permanentes após a finalização das obras, conforme informação fornecida pelo empreendedor durante a audiência pública da fase 2 (LASCHEFSKI, 2006).
} 
A chamada auto-segregação da população de alta renda é uma tendência observada no processo de ocupação do espaço no eixo sul da RMBH. ${ }^{20}$ Entretanto, isso não significa que os condomínios sejam excluídos dos mecanismos de regulação do Estado, mesmo que este assuma, com freqüência, o papel de coadjuvante no processo.

O lançamento do Alphaville 2 surge quando algumas das condicionantes do licenciamento ambiental da etapa 1 não haviam sido cumpridas, embora já tivesse iniciado o processo de ocupação da área. Voltam à tona as mesmas preocupações que já haviam estado no centro do debate sobre a viabilidade ambiental do Alphaville 1: qual o impacto regional de um empreendimento desse tipo, em que pese sua lenta ocupação, particularmente nos povoados tradicionais existentes no entorno e no acréscimo de tráfego na rodovia, sua principal via de acesso? Não seria esse um impacto ambiental negativo de magnitude tal que inviabilizasse sua implantação? No caso de Nova Lima, essa colocação é particularmente pertinente. Considerando a realidade de seu meio físico e a decisão de tornar a região uma unidade de conservação de uso sustentável, como superar os conflitos?

A história do Alphaville 2 tem início no processo conflituoso que marcou a primeira etapa. De acordo com Acselrad (2004, p.26), esse conflito, como tantos outros, tem a ver com o rompimento do "acordo simbiótico" entre as diferentes práticas sociais dispostas no espaço, "em função da denúncia de efeitos indesejáveis da atividade de um dos agentes sobre as condições materiais dos exercícios das práticas de outros agentes". Entretanto, para alguns autores, essa certeza sobre os efeitos indesejáveis de uma atividade sobre o ambiente está quase sempre repleta de valores morais ou de disposições legais, mais do que de certezas técnicas, pois, segundo Ewald (1992), as generalizações na área ambiental têm a ver com um debate sobre valores e não sobre respostas definitivas.

A oportunidade que a audiência pública convocada pela Amda deu a todos - setor público, comunidade ou o próprio mercado - foi a de ver explicitados, naquela oportunidade, o jogo de forças e as relações de poder que surgem no licenciamento ambiental de um parcelamento do solo urbano. A população diretamente afetada pelo empreendimento tem seu fórum especial de participação na audiência pública, podendo influenciar na concessão da licença ambiental prévia dos empreendimentos, embora em muitos casos seja uma mera formalidade.

No caso do Alphaville 2, a audiência pública, realizada depois de cerca de dois anos em que o processo estava em análise, ocorreu quando uma série de decisões e negociações já estava em curso, tendo em vista uma falha do empreendedor na formalização do processo, possibilitando então a solicitação, por parte da Amda, de realização da audiência, o que foi acatado pelo Copam.

Do ponto de vista dos empreendedores, o licenciamento ambiental é um processo muito lento que torna inviáveis empreendimentos dessa natureza, tendo em vista o montante de recursos investidos. Ou seja, segundo os empreendedores, a aprovação e implantação da etapa I já evidenciavam a viabilidade ambiental da etapa II. Essa associação levanta a discussão sobre o efeito cumulativo do empreendimento para o ambiente diretamente afetado e seu entorno, tendo em vista que não há referência de sua capacidade de suporte.

A imprensa publicou várias notícias sobre a audiência pública, pois ficou demonstrado na comunidade que as opiniões eram divergentes quanto aos benefícios para a região.

\section{Expansão da Alphaville Il é polêmica}

A Lagoa dos Ingleses Empreendimentos Imobiliários realiza hoje, às $14 \mathrm{~h} 30$, audiência pública no auditório do Sebrae, em Nova

\footnotetext{
20 Mendonça (2003, p. 133) assume como auto-segregação o que Gist e Fava (1964) denominaram "segregação voluntária", que ocorre quando um indivíduo, por sua própria iniciativa, procura conviver com outros semelhantes a ele e afastado daqueles que são diferentes em aspectos que, para ele, são fundamentais.
} 
Lima, Região Metropolitana de Belo Horizonte (RMBH), para elucidar o projeto de expansão Alphaville II, vinculado ao empreendimento Alphaville Lagoa dos Ingleses. A sessão foi requerida pela Associação Mineira de Defesa do Meio Ambiente (Amda), alegando estarem incompletos e desatualizados os estudos de impacto ambiental feitos pela empreendedora. De acordo com a superintendente executiva da entidade, Maria Dalce Ricas, a intenção da Amda é entregar um documento ao Conselho de Política Ambiental (Copam), relativo à primeira etapa do Alphaville Lagoa dos Ingleses - localizado no entroncamento da BR-356 com BR-040 -, retificando e fornecendo mais informações sobre "a fragilidade" dos estudos ambientais que o empreendedor forneceu à época (1997) (Diário do Comércio, 06/05/2004).

Várias questões foram levantadas naquela oportunidade, tais como porte do empreendimento, extensão do impacto regional, capacidade de suporte da lagoa para um novo uso de recreação e lazer às suas margens, tratamento dos esgotos, coleta e destino final dos resíduos, efeito, sobre a vazão da lagoa, da impermeabilização prevista no sistema viário e na ocupação dos terrenos, impacto, sobre a fauna local, da interferência nos seu habitat, impactos da geração e atração de tráfego sobre a rodovia BR-040, quando da plena ocupação do empreendimento, e, finalmente, discussão sobre os muros que confirmam o seu isolamento do entorno.

É possível o licenciamento ambiental discutir a viabilidade ambiental de empreendimentos sem a definição prévia do município de seu zoneamento de uso e ocupação do solo? A conclusão de avaliação de impacto ambiental fica prejudicada em termos socioeconômicos quando não se sabe qual projeto o município tem para a ocupação de seu território?

Os empreendedores e os analistas ambientais responsáveis pelos estudos técnicos referentes ao licenciamento ambiental entrevistados (PEIXOTO, 2005) concordam sobre a importância das definições refe- rentes ao uso e à ocupação do solo pelos governos locais no processo, como se registra a seguir:

Um município que tenha planejamento facilita o processo de análise da viabilidade ambiental dos loteamentos. O Plano Diretor da cidade e sua legislação complementar deveriam nortear o Plano de Negócio do empreendimento e principalmente o uso do solo urbano (entrevista com empreendedor, 2004).

O planejamento municipal forneceria aos analistas vários dos parâmetros mencionados, notadamente o zoneamento municipal, que indicaria áreas passíveis de ocupação, onde as perdas inevitáveis de recursos naturais sejam suportáveis para o município (entrevista com analista ambiental, 2004).

Em 20 de maio de 2004, o parecer técnico decorrente da análise do EIA/Rima sobre o licenciamento ambiental da etapa 2 do Alphaville foi encaminhado ao Conselho Consultivo da APA Sul, reunido em caráter extraordinário, tendo em vista que a manifestação do Conselho é condição para o encaminhamento do processo à Câmara de Atividades de Infra-estrutura - CIF/Copam, uma das sete câmaras especializadas que integram a estrutura do Copam. ${ }^{21}$

Ao mesmo tempo, as organizações nãogovernamentais envolvidas na discussão, ${ }^{22}$ representadas pela Amda, deram continuidade à mobilização em torno do licenciamento ambiental do Alphaville 2, divulgando na imprensa e em seu portal na Internet informações sobre o andamento do processo e sobre os possíveis impactos do empreendimento em sua área de influência.

No portal da Amda, ${ }^{23}$ foi veiculada a notícia: "Prefeitura de Nova Lima pressiona Conselho da APA Sul", deixando claro que "o único interesse da Prefeitura no licenciamento da etapa II do Alphaville é econômico, especialmente em decorrência da grande parcela de IPTU que o município passará a arrecadar." O portal registra que o empreendimento será implantado numa

\footnotetext{
21 Sobre a estrutura técnica e administrativa e as competências do Copam, consultar o Decreto n. 39.490, de 13 de março de 1998.

${ }^{22}$ A audiência pública foi solicitada pela Amda, pela Asturies (Associação para o Desenvolvimento do Turismo Ecológico Sustentável da Encosta da Serra) e Fundação Biodiverditas.

23 Em 21-05-2004, no portal <www.amda.org.br>.
} 
região que já sofre impacto de outros projetos imobiliários e do turismo predatório, que "não podem ser quantificados, são irreversíveis e em sua maior parte não são mitigáveis e infinitamente maiores que a atividade mineradora" (AMDA/ASSESSORIA DE IMPRENSA, 21/05/2004).

As questões levantadas pela Amda são pertinentes. Na ausência do suporte do planejamento local e regional, as decisões do licenciamento ficam restritas ao controle da degradação ambiental com a implantação e ocupação dos loteamentos, particularmente no que diz respeito ao saneamento básico, à geração de resíduos, drenagem pluvial e ao cumprimento das normas ambientais e urbanísticas porventura existentes. Por trás da gestão ambiental e da aplicação de seus instrumentos está, como afirma Jacobi (2002, p. 384), "a forma como as pessoas percebem ou não a existência de agravos ambientais, as inter-relações que os moradores estabelecem com esses agravos e as soluções propostas para a resolução de problemas".

O desdobramento desta posição, noticiado pela imprensa, foi o recurso administrativo impetrado pela Amda junto ao plenário do Conselho de Política Ambiental - Copam contra decisão da Câmara de Infra-Estrutura - CIF, que concedeu Licença de Instalação à expansão do Alphaville, no dia 08/07/2005. No recurso apresentado, a entidade solicita ampliação dos estudos ambientais, de forma a contemplar os "impactos radiais" do empreendimento, além de questionar a ausência de parecer técnico do IEF quanto aos impactos ambientais sobre a flora e a fauna e alertar sobre o descumprimento de condicionantes da primeira etapa. Um item interessante que traz novamente à tona a discussão sobre a gestão refere-se à responsabilidade quanto à implantação de aterro sanitário, originalmente do empreendedor, mas posteriormente repassado por convênio à Prefeitura de Nova Lima. Tal convênio, entretanto, não fornece à prefeitura condições de realizar a obra. O Estado, através da CIF do Copam, não entra na questão por entender que se tratar de um problema entre prefeitura e empreendedor, o que é contestado pela Amda.
Enquanto se discutia no Copam o licenciamento ambiental do Alphaville 2, outros empreendimentos imobiliários localizados no município de Nova Lima eram analisados, sem a mesma polêmica gerada pelo Alphaville. Mesmo município, mesmas restrições ambientais, maiores ou menores restrições com relação ao relevo a às condições de solo e prevendo escalas diferenciadas de efeitos ambientais negativos em sua área de influência. Diferentes abordagens, embora se tratasse de realidades ambientais semelhantes. O que mudou? Buscar essa resposta pode conduzir à identificação das fragilidades do licenciamento ambiental e indicar formas para usar todo o seu potencial na prática da gestão territorial.

\section{Considerações finais}

Embora as legislações ambiental e urbana tenham evoluído no sentido de maior articulação entre elas, observa-se que há um longo caminho a ser percorrido, apesar dos evidentes ganhos. Os mecanismos de regulação ambiental, pensados para atividades produtivas convencionais, são ainda frágeis para lidar com a produção do espaço urbano, em especial nas periferias urbanas (pobres ou ricas), em contextos de ausência de instrumentos de planejamento supralocal ou metropolitano. Os procedimentos usuais da legislação ambiental, como o licenciamento, mostram-se pouco adequados para o trato da complexidade da expansão urbana. Por outro lado, a existência de audiências públicas, ainda que de forma limitada, vem possibilitando a explicitação de conflitos e o aparecimento de possibilidades de alianças.

A inserção das questões urbanas na regulação ambiental está ainda em fase inicial, pois com freqüência a cidade é tratada como um dos principais agentes de degradação ambiental e, por isso, os conflitos decorrentes da oposição da cidade ao ambiente no processo de licenciamento resultam da concepção que ainda prevalece de existência de uma natureza natural, objeto central de preservação. Como afirma um analista ambiental: "uma das dificuldades de aprovar um projeto urbanístico no Co- 
pam decorre do fato de que a maioria dos técnicos que trabalham no licenciamento ambiental não gosta da cidade". ${ }^{24}$

O não gostar da cidade evidencia as dificuldades observadas na prática da gestão ambiental, quanto o objeto de licenciamento é a expansão urbana. Contudo, essa não é uma opinião geral, embora predomine, nessa prática e na legislação que lhe dá suporte, a defesa de uma natureza "natural", que dificilmente existe. Associar os problemas ambientais à produção do espaço urbano indica, por outro lado, a necessidade de refletir sobre as origens dessa relação, que reproduz as rupturas entre o homem e a natureza, evidenciada pelo fato de a natureza estar progressivamente perdendo seu valor de uso para ser tratada como mercadoria e elemento que agrega valor ao espaço produzido. A atuação do Estado tem se voltado para a ampliação de sua função normativa e de controle, estabelecendo novos procedimentos, revendo e atualizando sua legislação. Mas essa atuação se realiza sem que se interfira nas questões de fundo associadas às condições de reprodução social em termos amplos. Sempre vale recordar que em uma sociedade de classes o "Estado age [...] de acordo com as relações de força entre as classes e grupos sociais, geralmente em favor da fração hegemônica das classes dominantes" (CASTELLS, 1978, p. 3).

Finalmente, ainda no que se refere aos conflitos socioambientais envolvendo a atividade imobiliária, muitas vezes nem sequer caracterizados como tal, a participação dos grupos sociais é bastante diversificada e cheia de ambigüidades. Não há uma defi-

\section{Referências bibliográficas}

ACSELRAD, H. Conflitos ambientais: a atualidade do objeto. In: ACSELRAD, $\mathrm{H}$. (Org.). Conflitos ambientais no Brasil. Rio de Janeiro: Ed. Relume Dumará, Fundação Heinrich Boll, 2004. nição clara da figura do atingido, do grupo social que perde com o empreendimento, como na implantação de barragens ou em outros conflitos derivados de injustiças ambientais. Existe, muitas vezes, a identificação dos grupos sociais consumidores dos produtos - as moradias, os lotes, o loteamento fechado "seguro" e exclusivo - com as posições dos empreendedores. Tais grupos, usualmente, ao se verem como investidores, apóiam ações que podem apontar para ganhos patrimoniais, mas, dependendo das circunstâncias, podem ver na regulação urbanística/ambiental, ou seja, no Estado, uma garantia de qualidade do investimento imobiliário realizado. Neste sentido, o licenciamento pode transformarse numa "certificação ambiental".

Os grupos sociais indiretamente atingidos pelas transformações sociais e espaciais decorrentes do empreendimento podem representar interesses difusos, cujas possibilidades de alianças com outros grupos dependerão de cada contexto específico. A naturalização das relações de propriedade faz a desigualdade no acesso à terra e à habitação parecer apenas uma questão fruto das disparidades sociais, o que é parcialmente verdadeiro. A noção de que a reprodução dos espaços cada vez mais elitizados e segregados contribui para a elevação dos patamares de valorização fundiária e, conseqüentemente, para alimentar a exclusão não é clara para a maioria da população. Aliás, corresponde a um nível de abstração tão grande quanto a noção de função social de propriedade presente na Constituição de 1988 e, em grande parte, da política territorial urbana desde então.

BALL, M. Differential rent and the role of landed property. International Journal of Urban and Regional Research, London, Edward Arnold, 1 (3), p. 380403, 1977.

\footnotetext{
${ }^{24}$ Depoimento espontâneo recolhido em contato informal entre a autora e representante da sociedade civil, que integra a Câmara de Infra-estrutura Urbana - CIF/COPAM.
} 
BERNARDES, L. Política urbana: uma análise da experiência brasileira. Análise e Conjuntura, Rio de Janeiro, v. 1, n.1., p.83119, jan. /abr. 1986.

CALDEIRA, T. P. R. Enclaves fortificados: a nova segregação urbana. Novos Estudos CEBRAP, n. 47, p. 179-192, 1997.

CAMARGOS, R. Nascimento da APA Sul RMBH: o poder da polêmica. In: ACSELRAD, H. (Org.). Conflitos ambientais no Brasil. Rio de Janeiro: Ed. Relume Dumará,Fundação Heinrich Boll, 2004.

CARNEIRO, E. J. A "oligarquização" da política ambiental mineira. In: ZHOURI, A.; LASCHEFSKI, K.; PEREIRA, D. A insustentável leveza da política ambiental; desenvolvimento e conflitos sócioambientais. Belo Horizonte: Autêntica, 2005, p.65-88.

CASTELLS. M. City, class and power. Londres: The Macmillan Press, 1978.

COSTA, H. S. M. Natureza, mercado e cultura: caminhos da expansão metropolitana de BH. In: MENDONÇA, J. G.; GODINHO, M. H. L. (Orgs.). População, espaço e gestão na metrópole: novas configurações, velhas desigualdades. Belo Horizonte: PUC Minas, 2003, p. 159-179.

Mercado imobiliário, Estado e natureza na produção do espaço metropolitano. In: COSTA, H. S. M. et al. (Orgs.). Novas periferias metropolitanas. Belo Horizonte: Editora C/ Arte, 2006.

EWALD, F. L' expertise une illusion nécessaire. Paris: Autrement, 1992.

FERREIRA, M.B. A proteção ao patrimônio natural urbano: estudo de caso sobre a Serra do Curral. Dissertação (Mestrado em Geografia). Belo Horizonte: IGC/UFMG, 2003.

FREITAS, E. S. M. A reprodução social da metrópole em Belo Horizonte: APA Sul RMBH, mapeando novas raridades. Dissertação (Mestrado em Geografia). Belo Horizonte: IGC/UFMG, 2004.

GIDDENS, A. As consequências da modernidade. São Paulo: Ed. da Unesp, 1991.
HARVEY, D. Justice, nature and the geography of difference. Blackwell Publishers, 1996.

JACOBI, P. Meio ambiente urbano e sustentabilidade: alguns elementos para reflexão. In: CAVALCANTI, C. (Org.). Meio ambiente, desenvolvimento sustentável e políticas públicas. São Paulo: Cortez, 2002, p. 384-390.

LASCHEFSKI, K. A sustentabilidade geográfica de condomínios na zona metropolitana de Belo Horizonte. In: COSTA, H. S. M. et al. (Orgs.). Novas periferias metropolitanas. Belo Horizonte: Editora C/ Arte, 2006, p. 313-338.

LEFEBVRE, $H$. The production of space. Blackwell Publishers, 1991.

A revolução urbana. Belo Horizonte: Ed. UFMG, 1999.

LIPIETZ, A. Le tribut foncier urbain. Paris: Maspero, 1974.

LOJKINE, J. O estado capitalista e a questão urbana. São Paulo: Martins Fontes, 1981.

MACHADO, P. A. L. Direito ambiental brasileiro. São Paulo: Malheiros Editores, 1998.

MARES GUIA, V. R. A gestão na Região Metropolitana de Belo horizonte: avanços e limites. In: FERNANDES, E. (Org.). Direito urbanístico e política urbana no Brasil. Belo Horizonte: Del Rey, 2000, p.407-426.

MENDONÇA, J. G.; PERPÉTUO, I. H. O.; VARGAS, M. C. A periferização da riqueza na metrópole belo-horizontina: falsa hipótese? In: SEMINÁRIO SOBRE A ECONOMIA MINEIRA, 11, 2004, Diamantina. Anais... Belo Horizonte: Cedeplar/UFMG, 2004.

MENDONÇA, J. G. Belo Horizonte: a metrópole segregada. In: MENDONÇA, J. G.; GODINHO, M. H. L. (Orgs.). População, espaço e gestão na metrópole: novas configurações, velhas desigualdades. Belo Horizonte: PUC Minas, 2003, p. 119-58.

MONTE-MÓR, R. L. Urbanização extensiva e lógicas de povoamento: um olhar ambiental. 
In: SANTOS, M.; SOUZA, M. A.; SILVEIRA, M. L. (Orgs.). Território, globalização e fragmentação. São Paulo: Hucitec/Anpur, 1994.

PEIXOTO, M. C. D. Licenciamento ambiental e expansão urbana: um estudo em Nova Lima, Região Metropolitana de Belo Horizonte, MG. Dissertação (Mestrado em Geografia). Belo Horizonte: IGC/UFMG, 2005.

REZENDE, L. N. Alphaville Lagoa dos Ingleses. Um novo cenário de um velho modo de vida. Monografia (Trabalho de Conclusão de Curso). Belo Horizonte: IGC/ UFMG, 2004.

SHIVA, V. Biopirataria. Pilhagem da natureza e do conhecimento. Petrópolis: Vozes, 2001.

SINGER, P. Economia política da urbanização. São Paulo: Brasiliense, 1973.

SOMARRIBA, M. M. Lutas urbanas em Belo

Horizonte. Belo Horizonte: Vozes/Fundação João Pinheiro, 1984.

STEINBERGER, M. A relação meio ambiente

- meio urbano: do global para o local. Belo
Horizonte: Fundação João Pinheiro, 2000. Mimeografado. [Texto produzindo para o Curso de Gestão Urbana e Municipal, promovido pela ESAF, WBI, Ipea e CEF].

SWYNGEDOUW, E. A cidade como um híbrido: natureza, sociedade e urbanizaçãocyborg. In: ACSELRAD, H. (Org.). A duração das cidades; sustentabilidade e risco nas políticas urbanas. Rio de Janeiro: DP\&A, 2001.

TOPALOV, C. Les promoteurs immobiliers. Paris: Mouton, 1974.

VILLASCHI, J. Novas modalidades de urbanização e sua inserção regional: o condomínio Alphaville Lagoa dos Ingleses, Nova Lima-MG. In: CASTRIOTA, L. B. (Org.). Urbanização brasileira: redescobertas. Belo Horizonte: C/Arte, 2003, p.159-174.

ZHOURI, A.; LASCHEFSKI, K.; PAIVA, A. Uma sociologia do licenciamento ambiental: o caso das hidrelétricas em Minas Gerais. In: ZHOURI, A.; LASCHEFSKI, K.; PEREIRA, D. (Orgs.). A insustentável leveza da política ambiental; desenvolvimento e conflitos sócio-ambientais. Belo Horizonte: Autêntica, 2005, p.89-116.

\section{Resumen}

Dinámica inmobiliaria y regulación ambiental: una discusión a partir del eje-sur de la región metropolitana de Belo Horizonte

El trabajo trae, inicialmente, una breve discusión teórica sobre la producción del espacio urbano y la emergencia de la regulación ambiental, principalmente respecto a la expansión urbana. A continuación, son discutidos algunos instrumentos de regulación ambiental - en especial o licenciamiento de actividades -, que han hecho emerger prácticas sociales diversificadas, articulando intereses económicos, el Estado y grupos sociales orientados a la protección ambiental. Se enfatiza el carácter contradictorio de la intervención del Estado y se discuten los límites y posibilidades de acción de los movimientos sociales organizados en torno a la reproducción de las condiciones de expansión urbana. El artículo utiliza el caso del crecimiento metropolitano en el eje-sur de Belo Horizonte para evidenciar los conflictos en torno a las formas de apropiación y uso del suelo urbano, así como los expedientes adoptados por el capital inmobiliario para agregar valor al producto, reforzando mecanismos conocidos de elitización y exclusión. Se discute, incluso, si hay posibilidades de reversión de tal cuadro a partir de la participación y negociación de los conflictos entre los agentes sociales involucrados.

Palabras-clave: Política ambiental. Mercado inmobiliario. Participación. Conflicto. 


\begin{abstract}
Real-estate dynamics and environmental regulation: a discussion on the southern side of the Belo Horizonte Metropolitan Region

This article begins with a brief theoretical discussion of the production of urban space and the emergence of environmental regulamentation, especially in terms of urban expansion. Next, instruments of environmental regulation are discussed, especially the licensing of activities. Such instruments have created diverse social practices that articulate economic interests, the State, and social groups involved in environmental protection. The contradictory features of State intervention are also discussed, as well as the limits and possibilities of action by organized social movements involved in urban expansion. The text refers to a case study of metropolitan growth in the southern side of the city of Belo Horizonte, Brazil. In this context, conflicts involving land use and appropriation are discussed, as well as real-estate interests as they add value to their products, thus reinforcing well known forms of gentrification and exclusion. The article also brings up the question as to whether change is possible on the basis of participation and conflict negotiation among the social agents involved.
\end{abstract}

Keywords: Environmental policy. Real-estate market. Participation. Conflict.

Recebido para publicação em 02/10/2007.

Aceito para publicação em 12/11/2007. 